\title{
Intraoperative refractory hypotension in a patient with chronic use of low-dose prednisolone
}

\author{
Shingo Ito, Hiroyuki Seki* ${ }^{*}$, Yasushi Innami and Takashi Ouchi
}

Chronic steroid therapy may cause hypothalamicpituitary-adrenal (HPA) axis suppression, posing the potential risk of adrenal insufficiency in the perioperative period. Although there are inconsistent data to accurately predict the degree of adrenal suppression in patients receiving exogenous glucocorticoid therapy, patients treated with low-dose prednisone ( $\leq 5 \mathrm{mg} /$ day) have been considered to be at low risk of HPA axis suppression [1]. We report a case of intraoperative refractory hypotension in a patient with chronic use of prednisolone $3 \mathrm{mg} /$ day.

A 60-year-old woman $(148 \mathrm{~cm}, 52 \mathrm{~kg})$ underwent open reduction and internal fixation for a femoral neck fracture under general anesthesia. She had been taking prednisolone $3 \mathrm{mg} /$ day for 5 years for the treatment of rheumatoid arthritis. She had a history of hypertension, for which she took calcium-channel blockers, but was otherwise healthy.

On the day of surgery, she took her daily morning dose of prednisolone $3 \mathrm{mg}$.

Anesthesia was induced with propofol $120 \mathrm{mg}$ and fentanyl $100 \mu \mathrm{g}$ at 9 a.m. After the laryngeal mask airway was inserted, anesthesia was maintained using desflurane and a mixture of oxygen and nitrous oxide. Her blood pressure decreased from $140 / 90$ to $79 / 54 \mathrm{mmHg}$ after induction of anesthesia and remained low (systolic blood pressure $<70 \mathrm{mmHg}$ ) for $20 \mathrm{~min}$ and was unresponsive to repeated administration of ephedrine (a total of 16 $\mathrm{mg}$ ) and phenylephrine (a total of $0.5 \mathrm{mg}$ ). Hydrocortisone $50 \mathrm{mg}$ was administered, owing to the suspicion of adrenal insufficiency. Her systolic blood pressure increased to approximately $90 \mathrm{mmHg}$ within $10 \mathrm{~min}$ and was maintained at $>100 \mathrm{mmHg}$ after an additional administration of phenylephrine $0.1 \mathrm{mg}$. The patient awakened and was discharged from the operating room, soon after the completion of surgery.

* Correspondence: hshiroyukiseki@gmail.com

Department of Anesthesiology, Tokyo Dental College Ichikawa General Hospital, 5-11-13, Sugano Ichikawa, Chiba 272-8513, Japan
In this case, the patient developed refractory hypotension despite taking her daily corticosteroid replacement. Although the adrenocortical function was not assessed, it is probable that the HPA axis was suppressed, as the refractory hypotension rapidly improved after the administration of hydrocortisone. Patients receiving prednisone $\leq 5 \mathrm{mg}$ / day daily have a normal HPA axis response [2]. The recommendations do not recommend the administration of a stress dose of steroid or preoperative testing of adrenal function in these patients unless they exhibit signs of HPA axis suppression [1, 3]. However, a recent study demonstrated that adrenal insufficiency was observed in more than one third of patients during the ongoing use of lowdose prednisolone (5 mg/day) for rheumatoid arthritis [4]. Furthermore, a recent meta-analysis showed that the symptoms of adrenal insufficiency were not observed in most patients with glucocorticoid-induced adrenal insufficiency [5]. While the use of supraphysiologic glucocorticoids may increase the potential risk of steroid-induced side effects such as hyperglycemia, immunosuppression, and impaired wound healing, the results of these studies [4, 5], along with those of the present study, indicate the need for the administration of a stress dose of steroids in some patients with a "low risk" of adrenal insufficiency.

In conclusion, this case showed that under surgical stress, even patients on a low-dose, chronic regimen of prednisolone may require a stress dose of glucocorticoids. The patient provided written informed consent for the publication of this case report.

\section{Abbreviation \\ FGDs: Focus group discussions}

\section{Acknowledgements}

Not applicable.

\section{Authors' contributions}

SI participated in the care of the patient and obtained consent from the patient. SI and HS prepared the manuscript. YI and TO instructed in the writing of the manuscript. All authors read and approved the final manuscript. 


\section{Funding}

This case study did not receive any specific grant from funding agencies in the public, commercial, or not-for-profit sectors.

\section{Availability of data and materials}

Not applicable.

Ethics approval and consent to participate

Ethical approval was not required by our institution.

\section{Consent for publication}

The patient provided written informed consent for the publication of this case report.

\section{Competing interests}

The authors declare that they have no competing interests.

Received: 11 December 2019 Accepted: 26 December 2019

Published online: 03 January 2020

\section{References}

1. Coursin DB, Wood KE. Corticosteroid supplementation for adrenal insufficiency. JAMA. 2002;287:236-40.

2. LaRochelle GE Jr, LaRochelle AG, Ratner RE, Borenstein DG. Recovery of the hypothalamic-pituitary-adrenal (HPA) axis in patients with rheumatic diseases receiving low-dose prednisone. Am J Med. 1993:95:258-64.

3. Liu MM, Reidy AB, Saatee S, Collard CD. Perioperative steroid management: approaches based on current evidence. Anesthesiology. 2017;127:166-72.

4. Borresen SW, Klose M, Baslund B, Rasmussen AK, Hilsted L, Friis-Hansen L, et al. Adrenal insufficiency is seen in more than one-third of patients during ongoing low-dose prednisolone treatment for rheumatoid arthritis. Eur J Endocrinol. 2017;177:287-95.

5. Broersen LH, Pereira AM, Jorgensen JO, Dekkers OM. Adrenal insufficiency in corticosteroids use: systematic review and meta-analysis. J Clin Endocrinol Metab. 2015;100:2171-80.

\section{Publisher's Note}

Springer Nature remains neutral with regard to jurisdictional claims in published maps and institutional affiliations.

\section{Submit your manuscript to a SpringerOpen ${ }^{\circ}$ journal and benefit from:}

- Convenient online submission

- Rigorous peer review

- Open access: articles freely available online

- High visibility within the field

- Retaining the copyright to your article 